\author{
Military Technical College \\ Kobry El-Kobbah, \\ Cairo, Egypt
}

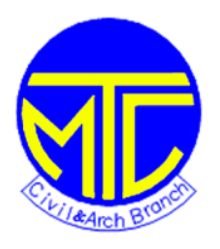

\title{
THREE-DIMENSIONAL FINITE ELEMENT ANALYSIS OF A TRIAL EMBANKMENT
}

\section{$8^{\text {th }}$ International Conference on Civil and Architecture Engineering ICCAE-8-2010}

\section{Abstract:}

Commonly finite element analyses of embankments and excavations are conducted as two-dimensional representations of the true three-dimensional problem, but very little work was done in determining the relative applicability of these solutions until recently, when three-dimensional programs and high-speed computers became available.

A trial embankment constructed in Vaasa (Finland) is analyzed in this paper. The main purpose of the construction was the testing and development of the calculation methods for the planning of road embankments. Settlements at the base level of the embankment were measured with settlement plates, and deeper in the ground with magnetic extensometer. The pore pressures are measured using open and closed piezometer tips installed at different depths. For the task of analysis carried out in this paper, a finite element computer program named (3-DFEP) is written. The program can solve three-dimensional coupled problems. Both the soil solids and the pore water are modeled by 8 -noded brick elements.

It was found that the results of three-dimensional analysis are more stable than do plane-strain ones. The settlement becomes approximately constant after about (600) days. The settlement predicted at that time is approximately (400) $\mathrm{mm}$ which is exactly recorded in the field while plane-strain results showed continuous increase in settlement after that time.

(1) Lecturer, Department of Building and Construction, University of Technology.

(2) Lecturer, Technical Institute / Al-Musayab.

(3) Lecturer, Civil Eng. Department, College of Eng., University of Al-Mustansirya. 


\section{Introduction:}

There are three general methods to deal with solutions to engineering problems. Those are empirical methods, closed from analytical techniques and numerical solutions. Numerical methods of stress analysis can be subdivided into two groups, direct numerical solutions of the developed differential equations, and matrix methods based on discrete-element idealization. The finite element method belongs to the second category (Bathe and Wilson, 1976). Today, the finite element method has become the most popular method for solving various differential equations. The method coupled with developments in computer technology has successfully been applied to the solution of steady and transient problems in linear and non-linear regions for one-, two- and three-dimensional domains (Dhatt, and Touzot, 1984).

\section{Discretization of Embankments:}

Discretization of a system such as an embankment on a "rigid" foundation is straightforward because the boundaries are defined, but in problems involving "infinite" media, e.g., embankment foundations in deep geologic masses, finite boundaries must be established. It is helpful if a relatively hard material is encountered at shallow depth, in which case the boundary for the finite element mesh is established at the interface of the relatively hard material, (Kulhawy, 1977)

It has been thought that relatively hard material can be defined as one, which has a modulus equal to 500 to 1000 times that of the overlying material, (Kulhawy, 1977). When a relatively hard material is not present, it is necessary to establish finite boundaries within which the significant influence of the construction operations occurs.

Dunlop and Duncan, (1969) suggested that the extension from the toe of slope should be at least three times the foundation depth (3D).

Figure (1) summarizes the results of several studies to determine the minimum extents required for modeling a finite media.

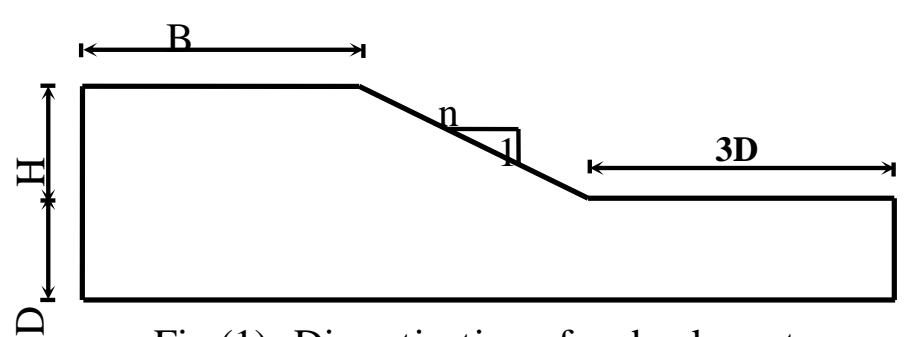

Fig.(1)- Discretization of embankments. 


\section{Two-Dimensional Versus Three-Dimensional Analyses:}

Commonly finite element analyses of embankments and excavations are conducted as two-dimensional representations of the true three-dimensional problem, but very little work was done in determining the relative applicability of these solutions until recently, when three-dimensional programs and high-speed computers became available.

For embankments and excavations which are very long, plane strain analyses of the transverse sections would be appropriate, except where discontinuities or other geological features intersect the transverse section obliquely. If this occurs, a plane strain analysis could only provide a very rough approximation because the problem is truly three-dimensional and should be analyzed as such, (Kulhawy, 1977).

For dam embankments within constrained valley walls, the behaviour is particularly complex because there are many modes of potential load transfer which can occur and affect the results. Limited analyses of homogeneous linear elastic dams in $\mathrm{V}$-shaped valleys with 1:1, 3:1 and 6:1 slopes was conducted to investigate these phenomena, (Lefebvre et al., 1973). The main results of this study indicate that:

1) Plane strain analyses of the maximum transverse section are reasonably accurate with valley walls at slopes of 3:1 or flatter but are not very accurate with valley walls at slopes of $1: 1$,

2) Plane stress analyses of the maximum longitudinal section do not provide accurate results, and.

3) Plane strain analyses of the maximum longitudinal section provide reasonably accurate results for all valley wall slopes investigated.

\section{Finite Element Equilibrium Equations:}

Compatibility of the displacements across the element boundaries is satisfied identically and force equilibrium is satisfied approximately.

\section{Solution of Static Equilibrium Equations: Elastic Equilibrium Equation:}

For static analysis, the equilibrium equation is:

$$
\{\mathbf{F}\}=[\mathbf{K}] *\{\boldsymbol{\delta}\}
$$

where:

$\{F\}=$ vector of nodal forces,

$[\mathrm{K}]=$ stiffness matrix, and

$\{\delta\}=$ vector of nodal displacements.

The element stiffness matrix which is referred to as $(\underline{\mathrm{KM}})$ in computer algorithms, can be simplified into (Zienkiewicz, 1977): 


\section{$\underline{K M}=\int B^{T}[D][B] d(v o l)$}

(2)

where [D] is the stress-strain (constitutive) matrix and [B] is the strain-displacement matrix.

Elasto-Plastic Model with Three- Dimensional Isoparametric Hexahedron Brick Elements:

In this model, the problem is discretized into eight-node brick elements. Each node in this element has three degrees of freedom of displacements in the $\mathrm{x}, \mathrm{y}$, and $\mathrm{z}$-directions,

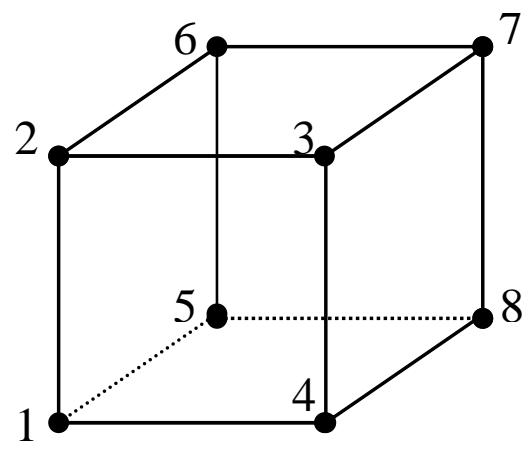

as shown in Figure (2).

Fig. (2) Local Node Numbering for 8-Node Brick Elements (from Smith and Griffiths, 1998).

The formulation of a three-dimensional stress analysis considers six components for each of stresses and strains and three components for displacement at a point.

For the derivation of the required matrices and vectors, the coordinates and local displacement fields of an element are interpolated using polynomials as follows (Hinton and Owen, 1977):

$$
\begin{gathered}
\{U\}=\sum_{i=1}^{n}[N i]\{\delta i\} \\
\{X\}=\sum_{i=1}^{n}[N i]\{X i\}
\end{gathered}
$$

where:

$\{\mathrm{U}\}=\left\{\begin{array}{lll}\mathrm{u} & \mathrm{v} & \mathrm{w}\end{array}\right\}^{\mathrm{T}}$, vector of local displacements in the $\mathrm{x}, \mathrm{y}$, and $\mathrm{z}$ directions, respectively.

$\mathrm{n}=$ number of nodes per element.

$\left\{\delta_{\mathrm{i}}\right\}=$ nodal displacements of node $(\mathrm{i})$. 
$\{X\}=\{x y z\}^{T}$, vector of local coordinates at any point.

$\left\{\mathrm{X}_{\mathrm{i}}\right\}=$ vector of coordinate of nodal point (i).

$\left[\mathrm{N}_{\mathrm{i}}\right]=$ interpolation function of nodal point (i).

The interpolation (shape) functions for an 8-noded three-dimensional hexahedron brick isoparametric element are (Reddy, 1984):

$$
\left.\begin{array}{rl}
\mathrm{N} 1 & =\frac{1}{8}(1-\xi)(1-\eta)(1-\zeta) \\
\mathrm{N} 2 & =\frac{1}{8}(1-\xi)(1-\eta)(1+\zeta) \\
\mathrm{N} 3=\frac{1}{8}(1+\xi)(1-\eta)(1+\zeta) \\
\mathrm{N} 4=\frac{1}{8}(1+\xi)(1-\eta)(1-\zeta) \\
\mathrm{N} 5=\frac{1}{8}(1-\xi)(1+\eta)(1-\zeta) \\
\mathrm{N} 6=\frac{1}{8}(1-\xi)(1+\eta)(1+\zeta) \\
\mathrm{N} 7=\frac{1}{8}(1+\xi)(1+\eta)(1+\zeta) \\
\mathrm{N} 8=\frac{1}{8}(1+\xi)(1+\eta)(1-\zeta)
\end{array}\right\}
$$

where $\quad-1 \leq \xi \leq 1,-1 \leq \eta \leq 1$, and $-1 \leq \zeta \leq 1$

The strain vector, for small strain theory, in a three-dimensional stress analysis is (Reddy, 1984):

(6)

$$
\{\boldsymbol{\varepsilon}\}=\left\{\begin{array}{l}
\boldsymbol{\varepsilon}_{\mathrm{x}} \\
\boldsymbol{\varepsilon}_{\mathrm{y}} \\
\boldsymbol{\varepsilon}_{z} \\
\boldsymbol{\gamma}_{\mathrm{xy}} \\
\boldsymbol{\gamma}_{\mathrm{yz}} \\
\boldsymbol{\gamma}_{\mathrm{zx}}
\end{array}\right\}=\left\{\begin{array}{l}
\partial \mathbf{u} / \partial \mathbf{x} \\
\partial \mathbf{v} / \partial \mathbf{y} \\
\partial \mathbf{w} / \partial \mathbf{z} \\
\partial \mathbf{u} / \partial \mathbf{y}+\partial \mathbf{v} / \partial \mathbf{x} \\
\partial \mathbf{v} / \partial \mathbf{z}+\partial \mathbf{w} / \partial \mathbf{y} \\
\partial \mathbf{u} / \partial \mathbf{z}+\partial \mathbf{w} / \partial \mathbf{x}
\end{array}\right\}
$$

The evaluation of the strain vector requires the evaluation of the derivatives given in equation (6).

The derivatives are calculated using a Jacobian transformation matrix which relates global coordinates $\mathrm{x}, \mathrm{y}$, and $\mathrm{z}$ derivatives to 1 ocal coordinate $\zeta, \eta$, and $\xi$ derivatives (Bathe and Wilson, 1976): 
$\left\{\begin{array}{l}\frac{\partial}{\partial \xi} \\ \frac{\partial}{\partial \boldsymbol{\eta}} \\ \frac{\partial}{\partial \zeta}\end{array}\right\}=[\mathbf{J}]^{\mathrm{e}}\left\{\begin{array}{c}\frac{\partial}{\partial \mathbf{x}} \\ \frac{\partial}{\partial \mathbf{y}} \\ \frac{\partial}{\partial \mathbf{z}}\end{array}\right\}$

where:

$[\mathbf{J}]^{\mathrm{e}}=$ the Jacobian matrix in Cartesian coordinates.

The strain-displacement relation is given as (Bathe and Wilson, 1976):

$$
\{\varepsilon\}=\sum_{i=1}^{n}\left[B_{i}\right]\left\{\delta_{i}\right\}
$$

where: $\mathrm{Bi}=$ The strain-displacement matrix ( Bathe and Wilson, 1976):

where:

$$
\left[B_{i}\right]=\left[\begin{array}{cccccccc}
N_{1,1} & 0 & 0 & N_{2,1} & . & . & . & 0 \\
0 & N_{1,2} & 0 & 0 & . & . & . & 0 \\
0 & 0 & N_{1,3} & 0 & . & . & . & N_{m, 3} \\
N_{1,2} & N_{1,1} & 0 & N_{2,2} & . & . & . & 0 \\
N_{1,3} & 0 & N_{1,1} & N_{2,3} & . & . & . & N_{m, 1} \\
0 & N_{1,3} & N_{1,2} & 0 & . & . & . & N_{m, 2}
\end{array}\right]
$$

$$
N_{i, j}=\frac{\partial N_{i}}{\partial x_{j}}
$$

The three normal and three shearing stresses are related to the corresponding strains through the stress-strain constitutive matrix D:

$$
\{\sigma\}=[D]\{\varepsilon\}
$$

For linear elasticity applications, D is given by: - 


$$
[D]=\frac{E(1-v)}{(1+v)(1-2 v)}\left[\begin{array}{cccccc}
1 & \frac{v}{1-v} & \frac{v}{1-v} & 0 & 0 & 0 \\
\frac{v}{1-v} & 1 & \frac{v}{1-v} & 0 & 0 & 0 \\
\frac{v}{1-v} & \frac{v}{1-v} & 1 & 0 & 0 & 0 \\
0 & 0 & 0 & \frac{1-2 v}{2(1-v)} & 0 & 0 \\
0 & 0 & 0 & 0 & \frac{1-2 v}{2(1-v)} & 0 \\
0 & 0 & 0 & 0 & 0 & \frac{1-2 v}{2(1-v)}
\end{array}\right]
$$

where:

$$
v=\text { Poisson's ratio. } \quad \mathbf{E}=\text { Young's modulus of elasticity, and }
$$

\section{Solution of Undrained Problems (Calculation of Excess Pore Water Pressure):}

The undrained condition pertaining to the beginning of the consolidation process is so important in soil mechanics that it merits special treatment.

Taylor (1974) has described a method of separating the stresses into pore pressures and effective stresses. The method uses, basically, the concept of effective stress in matrix notation; thus:

$$
\boldsymbol{\sigma}=\sigma^{\prime}+\boldsymbol{u}_{w}
$$

where:

$$
\begin{aligned}
\sigma & =\text { the total stress, } \\
\sigma^{\prime} & =\text { the effective stress, and } \\
u_{w} & =\text { the pore pressure. }
\end{aligned}
$$

The stress-strain relationship (Equation 10) can now be written in terms of the effective stresses as:

$$
\sigma^{\prime}=\underline{D^{\prime}} \varepsilon
$$

and

$$
u_{w}=\underline{\boldsymbol{D}_{\boldsymbol{u}} \boldsymbol{\varepsilon}}
$$

which combine to give:

where

$$
\sigma=D \varepsilon
$$




$$
\underline{D}=\underline{D^{\prime}}+\underline{D_{u}}
$$

For soils exhibiting linear elastic deformations, the matrix [D'] is the familiar elastic stress-strain matrix in terms of effective Young's modulus (E') and Poisson's ratio $\left(v^{\prime}\right)$.

The matrix $\left(\mathrm{D}_{\mathrm{u}}\right)$ contains the apparent bulk modulus of the fluid $\left(\mathrm{K}_{\mathrm{e}}\right)$ in the following locations (Smith and Griffithes, 1998):

$$
\left[D_{u}\right]=\left[\begin{array}{cccccc}
K_{e} & K_{e} & K_{e} & \mathbf{0} & \mathbf{0} & \mathbf{0} \\
K_{e} & K_{e} & K_{e} & \mathbf{0} & \mathbf{0} & \mathbf{0} \\
K_{e} & K_{e} & K_{e} & \mathbf{0} & \mathbf{0} & \mathbf{0} \\
\mathbf{0} & \mathbf{0} & \mathbf{0} & \mathbf{0} & \mathbf{0} & \mathbf{0} \\
\mathbf{0} & \mathbf{0} & \mathbf{0} & \mathbf{0} & \mathbf{0} & \mathbf{0} \\
\mathbf{0} & \mathbf{0} & \mathbf{0} & \mathbf{0} & \mathbf{0} & \mathbf{0}
\end{array}\right]
$$

assuming that the fourth, fifth, and the sixth columns correspond to the shear terms in a three-dimensional analysis.

To implement this method in this solution, it is necessary to form the global stiffness matrix using the total stress-strain matrix (D). Furthermore, the effective stresses for uses in the yield function are computed from incremental strains using the effective stress-strain matrix (D'). Excess pore pressures $\left(u_{w}\right)$ are simply computed from (Smith and Griffiths, 1998):

$$
u_{w}=K_{e}\left(\varepsilon_{x}+\varepsilon_{y}+\varepsilon_{z}\right)
$$

In order to compute pore pressures during undrained loading, it is necessary to update strains as well as stresses after each increment.

\section{Solution of Drained Problems (Coupled Problems):}

The element equations for Biot's consolidation problem are given by (Lewis and Schrefler, 1987):

$$
\left.\begin{array}{l}
\underline{\boldsymbol{K M}} \boldsymbol{r}+\underline{\boldsymbol{C}} u_{w}=\boldsymbol{f} \\
\underline{\boldsymbol{C}}^{\boldsymbol{T}} \frac{\boldsymbol{d r}}{\boldsymbol{d t}}-\underline{\boldsymbol{K} \boldsymbol{P}} u_{w}=\mathbf{0}
\end{array}\right\}
$$

where:

$$
\begin{aligned}
& r=\text { displacement vector, } \\
& f=\text { force vector, } \\
& C=\text { vector of nodal flows, } \\
& K P=\text { stiffness of pore fluid, } \\
& t=\text { time, and }
\end{aligned}
$$


$\mathrm{T}=$ transpose of a matrix

There are many methods available to integrate Equation (17) with respect to time. One of them is the simple linear interpolation function in time using the finite element as follows:

$$
\left.\begin{array}{l}
\theta \underline{K M r_{1}}+\theta \underline{C} u_{w}=(\theta-1) \underline{K M r_{0}}+(\theta-1) \underline{C} u_{w 0}+f \\
\theta \underline{C}^{T} r_{1}-\theta^{2} \Delta t \underline{K P} u_{w 1}=\theta \underline{C}^{T} r_{0}-\theta(\theta-1) \Delta t \underline{K P} u_{w 0}
\end{array}\right\}
$$

where (f) is assumed here to be independent of time and the second equation has been multiplied throughout by $(\theta)$ to preserve symmetry on the left-hand-side of Equation (18).

In the Crank-Nicolson type of approximation, $(\theta)$ is made equal to $1 / 2$ in both sides of Equation (18), leading to the recurrence relation:

$\left[\begin{array}{cc}\underline{K M} & \underline{C} \\ \underline{C}^{T} & -\frac{\Delta t}{2} \underline{K P}\end{array}\right]\left\{\begin{array}{c}r_{1} \\ u_{w 1}\end{array}\right\}=\left[\begin{array}{cc}-\underline{K M} & -\underline{C} \\ \underline{C} & -\frac{\Delta t}{2} \underline{K P}\end{array}\right]\left\{\begin{array}{c}r_{0} \\ u_{w 0}\end{array}\right\}+\left\{\begin{array}{c}2 f \\ 0\end{array}\right\}$

The approximation in the above equation can lead to oscillatory results. The oscillations can be smoothed out by using the fully implicit version of Equation (18) with $(\theta)$, which leads to the recurrence relation (Irons, 1996):

$$
\left[\begin{array}{cc}
\underline{K M} & \underline{C} \\
\underline{C}^{T} & -\Delta t \underline{K P}
\end{array}\right]\left\{\begin{array}{c}
r_{1} \\
u_{w 1}
\end{array}\right\}=\left[\begin{array}{cc}
0 & 0 \\
\underline{C}^{T} & 0
\end{array}\right]\left\{\begin{array}{c}
r_{0} \\
u_{w 0}
\end{array}\right\}+\left\{\begin{array}{c}
f \\
0
\end{array}\right\}
$$

\section{Incremental Formulation:}

In Equations (19) and (20), (f) is the total force applied and these equations are appropriate to linear systems. For non-linearity in which KM and /or KP in Equation (17) vary with time and (f) has to be applied in small increments $(\Delta f)$, if $(\Delta f)$ is the change in load between successive times, the incremental form of the first of the Equations (17) is (Hicks, 1995)

$$
\underline{K M} \Delta r+\underline{C} \Delta u_{w}=\Delta f
$$

where $(\Delta \mathrm{r})$ and $\left(\Delta \mathrm{u}_{\mathrm{w}}\right)$ are the resulting changes in displacements and excess pore water pressure, respectively. Linear interpolation in time using the $\theta$ - method yields (Hicks, 1995):

$$
\Delta r=\left[(1-\theta) \frac{d r_{0}}{d t}+\theta \frac{d r_{1}}{d t}\right] \Delta t
$$

The second of Equations (17) can be written at two time levels to give expressions for $\mathrm{dr}_{\mathrm{o}} / \mathrm{dt}$ and $\mathrm{dr}_{1} / \mathrm{dt}$. When this is done: 
$\underline{\boldsymbol{C}}^{\boldsymbol{T}} \Delta \boldsymbol{r}-\underline{\boldsymbol{K} \boldsymbol{P}}\left(u_{w}+\theta \Delta u_{w}\right) \Delta \boldsymbol{t}$

(23)

or

$\underline{C}^{T} \Delta r-\theta \Delta t \underline{K P} \Delta u_{w}=\Delta t \underline{K P} u_{w}$

Finally, the incremental form for Equations (19) and (20) is (Hicks, 1995):

$$
\left[\begin{array}{cc}
\underline{K M} & \underline{C} \\
\underline{C}^{T} & -\theta \Delta t \underline{K \boldsymbol{P}}
\end{array}\right]\left[\begin{array}{c}
\Delta r \\
\Delta u_{w}
\end{array}\right]=\left\{\begin{array}{c}
\Delta f \\
\Delta t \underline{\boldsymbol{K P}} u_{w}
\end{array}\right\}
$$

\section{Case Study - The Vaasa Trial Embankment:}

\section{Geometry - Instrumentation and Construction:}

A trial embankment was constructed in Vaasa (Finland) as presented in Figure (3). The main purpose of the construction was the testing and development of the calculation methods for the planning of road embankments. The trial embankment has a rectangular shape (see Figure 3). The height of the embankment is $2(\mathrm{~m})$ and the gradient of slopes is $1: 1.5$ and the length $25 \mathrm{~m}$. The instrumentation of the trial embankment is also presented in Figure (3).

Settlements at the base level of the embankment are measured with settlements plates, and deeper in the ground with magnetic extensometer. The pore pressures are measured using open and closed piezometer tips installed at different depths. The construction of the embankment took three days. Furthermore, extensive laboratory soil tests using the triaxial apparatus and the oedometer have been done in order to determine the soil parameters. 


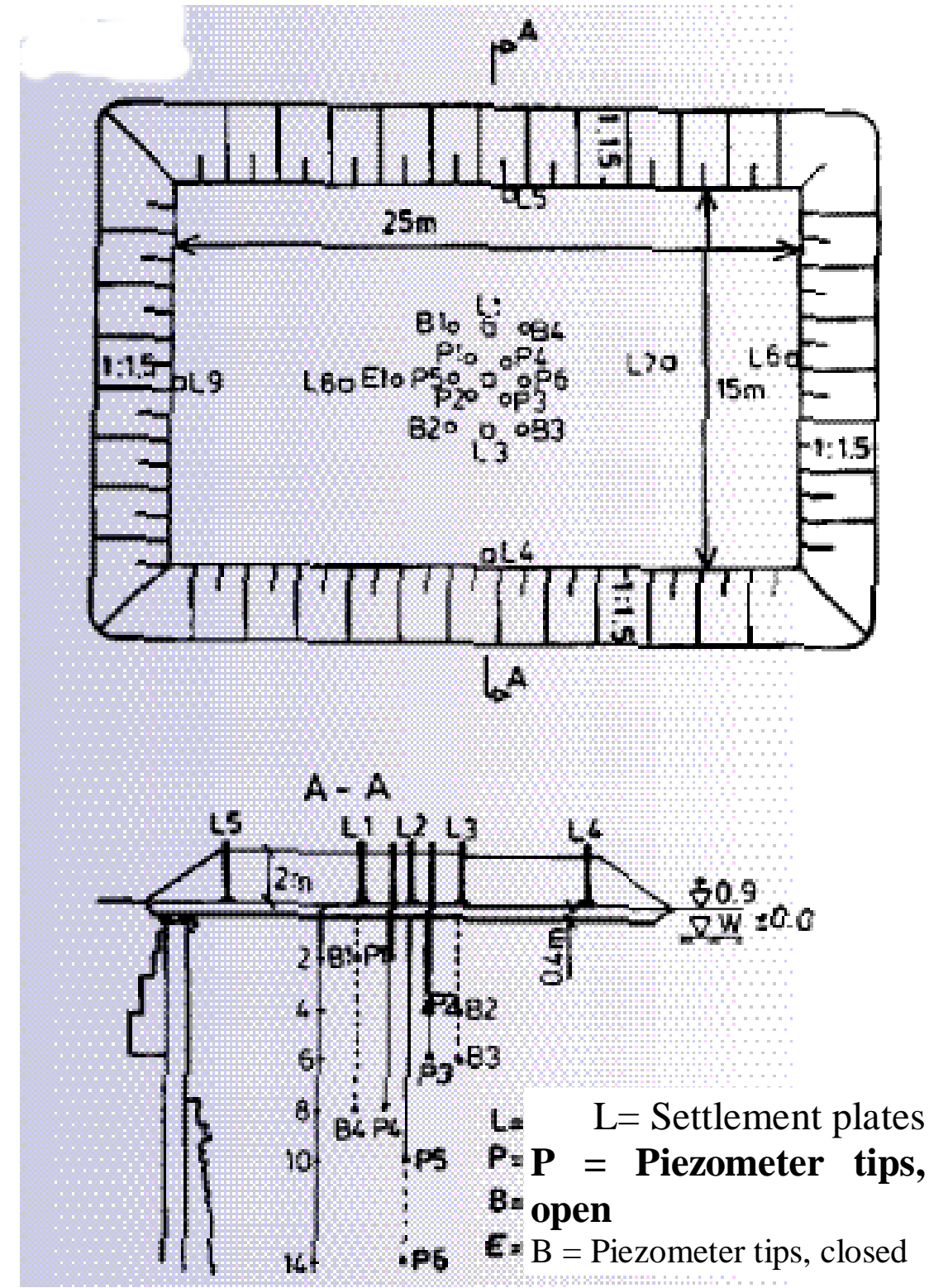

Fig. (3) - Geometry and instrumentation of Vasaa trial embankment, (Plaxis No. 7, 1999).

\section{Ground Conditions:}

The subsoil consists of more than $40 \mathrm{~m}$ thick layer of soft silty clay with high organic content and sulphur. The clay layer is homogeneous and most of the laboratory investigations are concentrated only to $15 \mathrm{~m}$ depth. The ground water level is $0.5 \mathrm{~m}$ below the original surface. The parameters used for the calculations are obtained from the results of oedometer tests. They are presented in Table (1). 
Table (1) - Model parameters used in the analysis, (after Vepsalanien et al., 2000).

\begin{tabular}{|c|c|c|c|c|c|}
\hline Layer & $\begin{array}{c}\mathrm{k}_{\mathrm{h}} \text { and } \mathrm{k}_{\mathrm{v}} \\
(\mathrm{m} / \mathrm{day})\end{array}$ & $\phi^{\mathrm{o}}$ & $\begin{array}{c}\mathrm{c} \\
(\mathrm{kPa})\end{array}$ & $\mathrm{e}_{\mathrm{o}}$ & $\lambda$ \\
\hline 1 & $\begin{array}{c}1.167 \mathrm{e}- \\
05\end{array}$ & 26 & 6 & 2 & 0.390 \\
\hline 2 & $\begin{array}{c}6.000 \mathrm{e}- \\
06\end{array}$ & 26 & 6 & 2 & 0.330 \\
\hline 3 & $\begin{array}{c}1.333 \mathrm{e}- \\
05\end{array}$ & 26 & 6 & 2 & 0.325 \\
\hline 4 & $\begin{array}{c}2.633 \mathrm{e}- \\
05\end{array}$ & 25 & 6 & 2 & 0.325 \\
\hline 5 & $\begin{array}{c}8.700 \mathrm{e}- \\
05\end{array}$ & 30 & 6 & 2 & 0.293 \\
\hline 6 & $\begin{array}{c}8.700 \mathrm{e}- \\
04\end{array}$ & 30 & 6 & 2 & 0.065 \\
\hline
\end{tabular}

where:

$\mathrm{k}_{\mathrm{v}}, \mathrm{k}_{\mathrm{h}}$ are vertical and horizontal coefficients of permeability,

$\phi=$ the angle of internal friction,

$\mathrm{c}=$ the cohesion,

$\mathrm{e}_{\mathrm{o}}=$ the initial void ratio, and

$\lambda=$ critical state parameter $=\mathrm{Cc} / 2.3$ in which $\mathrm{Cc}$ is the compression index.

\section{Calculations:}

For the task of analysis carried out in this paper, a finite element computer program named (3-DFEP) is written. The program can solve three-dimensional coupled problems. Both the soil solids and the pore water are modeled by 8 -noded brick elements. For the calculations with the finite element program (3-DFEP), the model parameters given in Table (1) are used. The determination of the parameters was done by extensive laboratory testing in Finland. The same set of parameters was used in the Cam Clay computations made by Vepsalainen et al., (2000). The overconsolidation ratio OCR is 1.45 .

The Vaasa embankment and the subsoil have been schematized using the mesh presented in Figure (4). In order to clarify the geometry, only one quarter of the mesh is 
presented.. The mesh consists of 8-node isoparametric brick elements. The calculations have been made considering three-dimensional effects. Each nodal point in the mesh has four degrees of freedom, three for displacements and the fourth is the pore water pressure. The program deals with the soil as an elasto-plastic material adopting MohrCoulomb failure criterion.

The right, left, front and back boundaries are represented by vertical rollers through which only vertical movements are allowed while the bottom boundary of the embankment foundation is assumed to be fixed. These boundaries are assumed to be impermeable concerning the pore water pressure.

Two-dimensional plane-strain elasto-plastic analysis was previously carried out using the computer program (PLAXIS- Version 7.0). The Cam clay model is adopted in the analysis and constant strain triangular elements were used to model the embankment and its foundation, (Plaxis No. 7, 2002).

PLAXIS Version 7.0 is a finite element package for two-dimensional analysis of deformation and stability in geotechnical engineering. It can handle geotechnical applications which require advanced constitutive models for the simulation for the nonlinear, time-dependent and anisotropic behaviour of soils. Excess pore pressures are computed during plastic calculations when undrained soil layers are subjected to loads.

In the following calculation step the load due to the weight of the embankment has been applied in an undrained state, followed by consolidation. The results are presented in two different shapes. The first is the time versus settlement curve shown in Figure (5). The calculated initial settlement is (120) $\mathrm{mm}$ (after the construction of the embankment), the measured one was (100) mm, (Vepsalainen et al., 2000). Besides, the settlement using the (PLAXIS) program is approximately (100) $\mathrm{mm}$. Figure (5) shows that the calculated settlement is quite the same as the measured one (11\% overrating). It can be observed that the results of three-dimensional analysis are more stable than do planestrain ones. The settlement becomes approximately constant after about (600) days. The settlement at that time is approximately (400) $\mathrm{mm}$ which is exactly recorded in the field while plane-strain results showed continuous increase in settlement after that time (as shown in Figure 5).

Figure (6) shows the variation of the average degree of consolidation for the foundation of the embankment (Uav.) with time. The value of (Uav.) approaches (95\%) after about (600) days.

The measured values of excess pore water pressure are not reliable as shown in Figure (7).

Figure (8) presents the isochrones of excess pore water pressure in the foundation of the embankment at different times. It can be seen that after about (600) days, the 
excess pore water pressure in the middle of the foundation (about $15 \mathrm{~m}$ beneath the embankment) becomes about ( $1 \mathrm{kPa})$, i.e., $(5 \%)$ of the initial excess pore water pressure generated by the embankment. This means that at that time, $(95 \%)$ of the consolidation process finished.

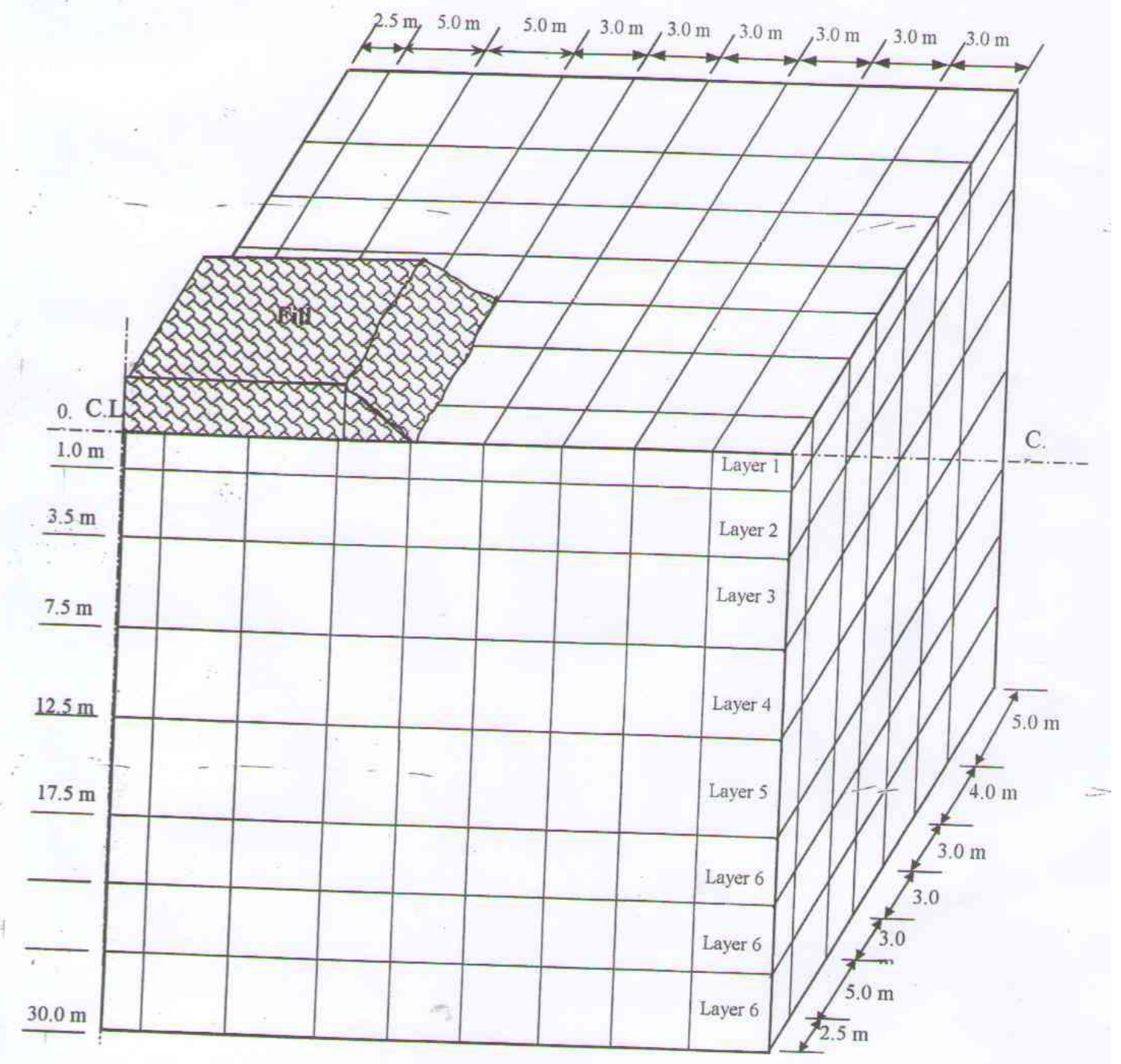

Fig. (4) - The finite element mesh. 


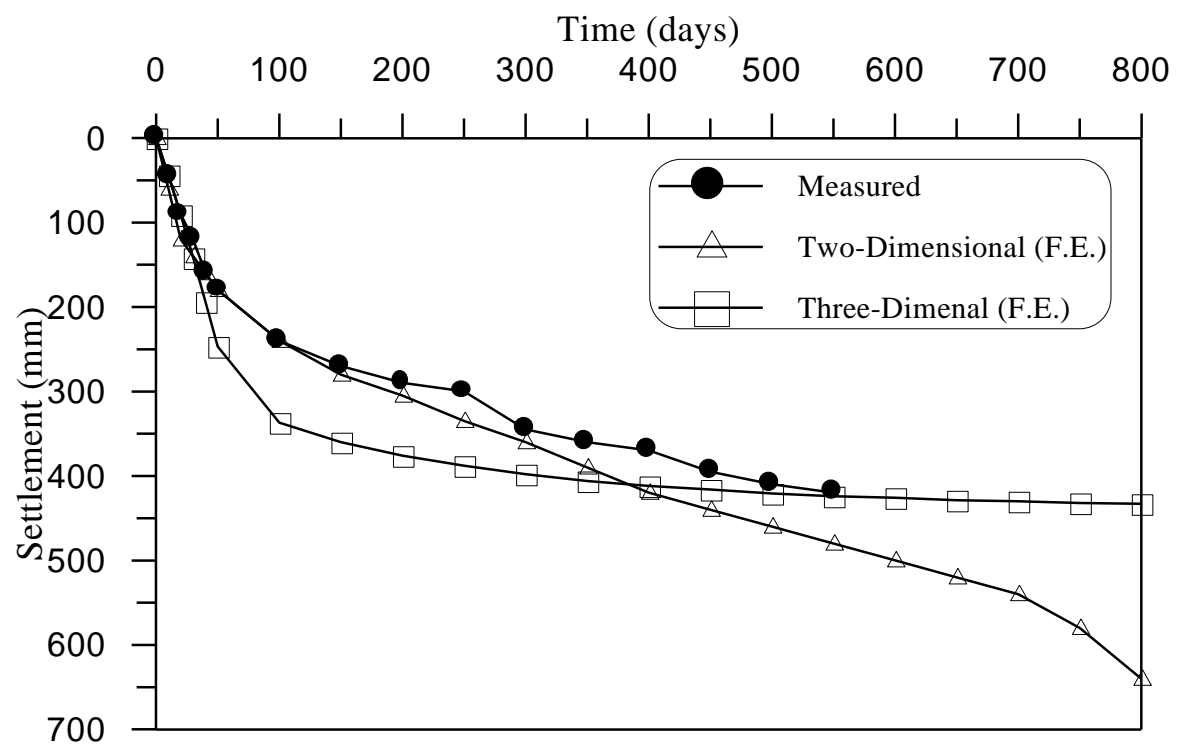

Fig. (5) - Time-settlement relationships.

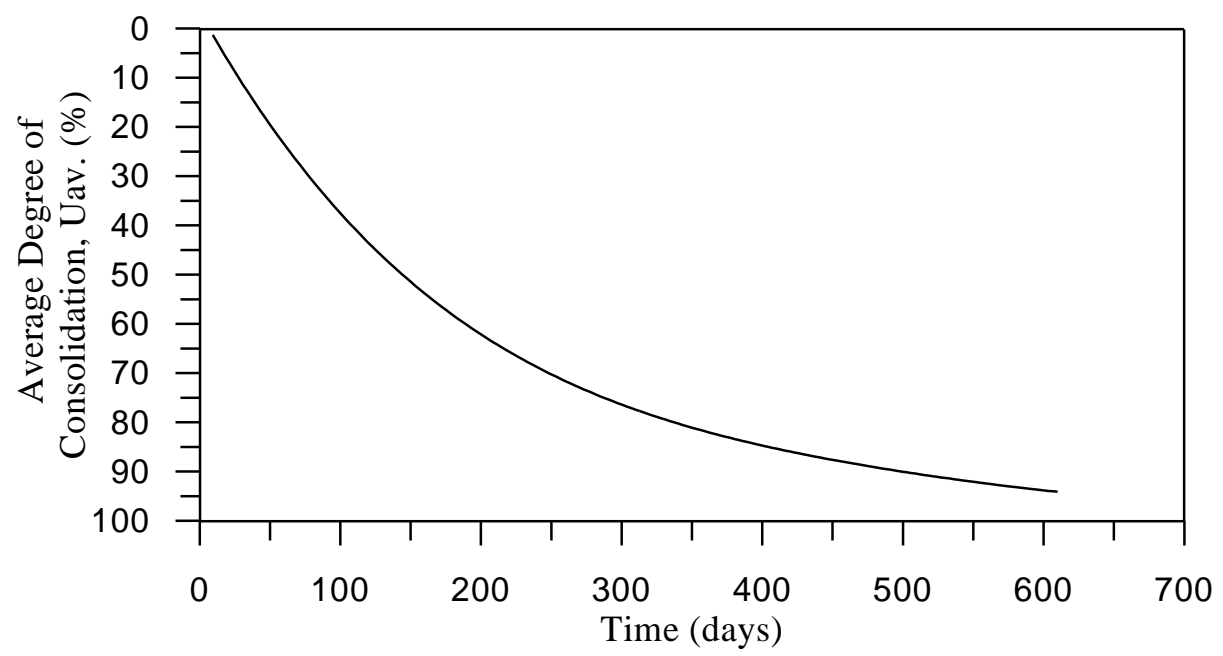

Fig. (6) - The average degree of consolidation-time relationship. 


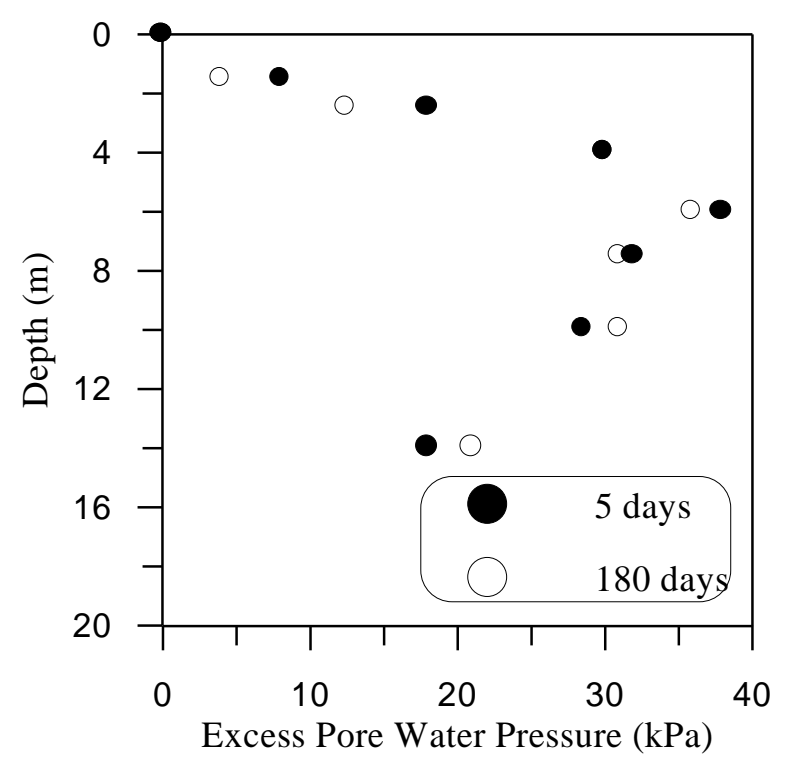

Fig. (7 ) - Measured pore water pressure.

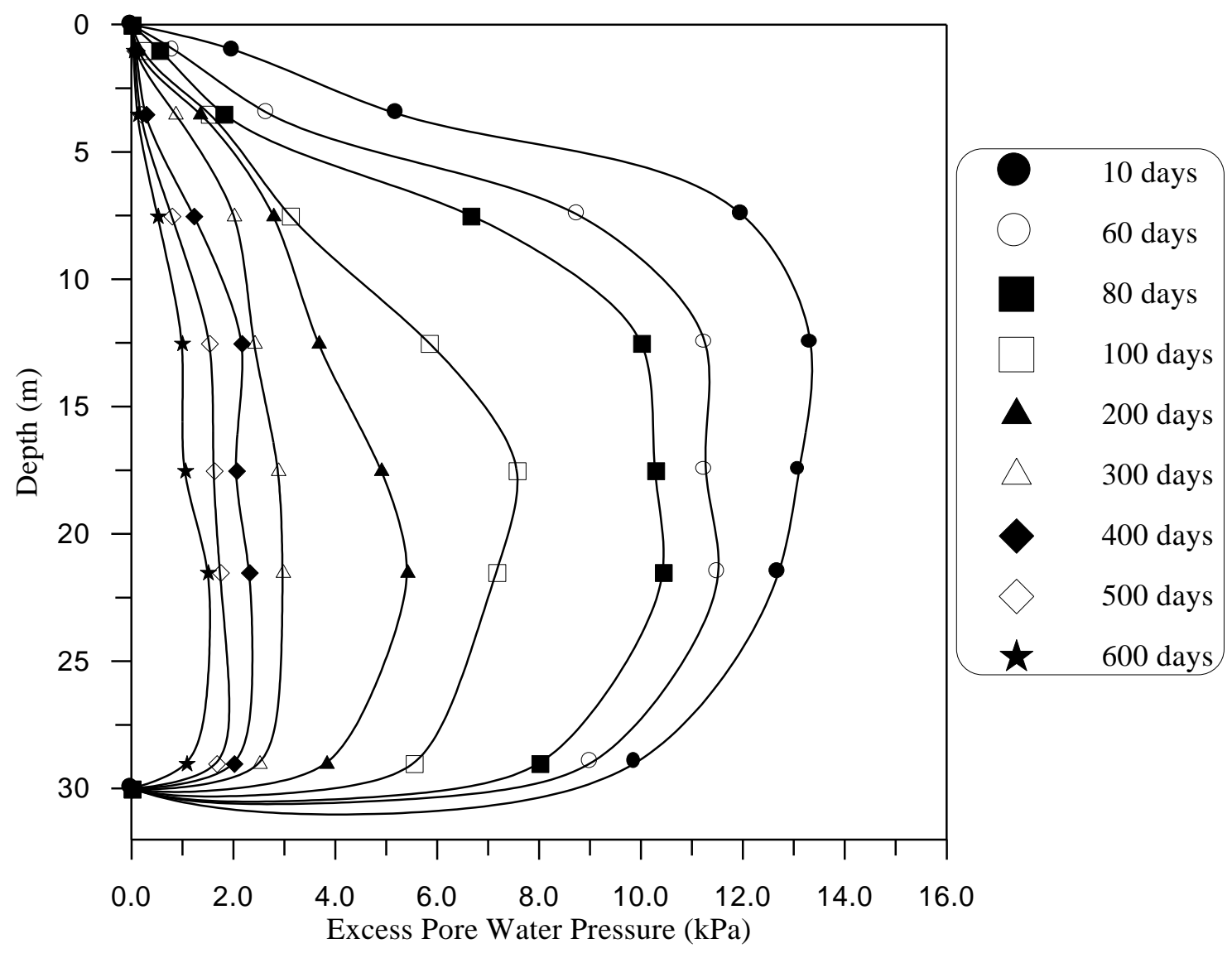

Fig. (8) - Isochrones of excess pore water pressure developed beneath the embankment. 


\section{Conclusions:}

A three-dimensional coupled elasto-plastic finite element analysis of a trial embankment is carried out in this paper. A computer program named (3-DFEP) is written. The program can solve three-dimensional coupled problems. Both the soil solids and the pore water are modeled by 8 -noded brick elements. The following conclusions are obtained:

1. The results of three-dimensional analysis are more stable than do plane-strain ones. The settlement becomes approximately constant after about (600) days. The settlement at that time is approximately (400) $\mathrm{mm}$ which is exactly recorded in the field while plane-strain results showed continuous increase in settlement after that time.

2. Considering the excess pore pressures, the pore pressure isochrones in the foundation of the embankment shows a uniform dissipation of excess pore pressures. It was found that after about (600) days, the excess pore water pressure in the middle of the foundation (about $15 \mathrm{~m}$ beneath the embankment) becomes about (1 kPa), i.e., (5\%) of the initial excess pore water pressure generated by the embankment. This means that at that time, $(95 \%)$ of the consolidation process finished.

\section{References:}

- $\quad$ Bathe, K. J. and Wilson, E. L., (1976), (Numerical Methods in Finite Element Analysis), Prentice-Hill Inc.

- Dhatt, G. and Touzot, G., (1984). (The Finite Element Method Displayed), John Wiley and Sons.

- Kulhawy, F. H., (1977), (Embankments and Excavations), chapter sixteen in "Numerical Methods in Geotechnical Engineering", edited by C. S. Desai and J. T. Christian, McGraw-Hill Book Comp. New York.

- Dunlop, P., and Duncan, J. M. (1969), "Slopes in Stiff- Fissured Clays and Shale", Journal of Soil Mechanics and Foundations Division, ASCE, Vol. 95. SM 2, pp. 467-491.

- Lefebvre, G., Duncan, J. M. and Wilson, E. L., (1973). (Three-dimensional Finite Element Analyses of Dams), Journal of Soil Mechanics and Foundations Division, ASCE, Vol. 99, No. SM7, p.p. 495-507.

- Lewis, R. W. and Schrefler, B. A., (1987). (The Finite Element Method in the Deformation and Consolidation of Porous Media), John Wiley and Sons.

- $\quad$ Plaxis No. 7, (2002). Report from Internet.

- Smith, I. M. and Griffiths, D. V., (1998). (Programming the Finite Element Method), third edition, John Wiley and Sons. 
- Smith, I. M. and Griffiths, D. V., (1998). (Programming the Finite Element Method), John Wiley and Sons, Great Britain.

- Vepsalainen, P., Arkima, O., Lojander, M. and Naatanen, A., (2000). (The Trial Embankments in Vaasa and Paimio-Finland), Proceedings of the tenth European Conference on Soil Mechanics and Foundation Engineering, Florence, Vol. 2, p.p. 633-640.

- Zienkiewicz, O. C., (1977). (The Finite Element Method), Mc-Graw-Hill Book Company, third edition. 